\title{
DESIGUALDADES DE GÉNERO: ESBOZO POR UN MAPA PROTEÓRICO ${ }^{1}$
}

\author{
Manuel Carlos Silva
}

\section{Resumen}

A pesar del relativo progreso, en términos legales y políticos, de la defensa de los principios de equidad de relaciones de género, recientes estudios a nivel nacional e internacional confirman las persistentes desigualdades de género en diversos contextos (laborales, interacciones cotidianas, valores y regulaciones simbólicas, encuadramientos institucionales).

En este artículo, después de una revisión, en una forma sintética y crítica, de algunos paradigmas teóricos que procuran explicar estas desigualdades (concepciones sóciobiológicas, psicológicas, en especial psicoanalíticas, estructural-funcionalistas, marxistas, neo-weberianas), el autor propone una articulación entre los conceptos de género y de clase. Esto implica la convergencia del modelo marxista con el feminista e, indirectamente, un cruce frutífero entre el posicionamiento (neo)marxista y weberiano, siendo este último articulable con la perspectiva interaccionista simbólica. Se sigue una breve retrospectiva histórica y la correlativa desconstrucción de las formas esencialistas, reificadoras y legitimadoras del statu quo.

Por fin, con una breve ilustracción sobre algunas desigualdades de género en Portugal, se esboza una hipótesis de que, más allá de los intereses inherentes a los mecanismos macro-económicos e institucionales de dominación, el control de la fuerza de trabajo femenina y los subsecuentes fenómenos de segregación y discriminación laboral y social se reproducen a diversos niveles: socio-estructural, organizacional / institutional e interactivo. A nivel micro e intermedio, el poder de la mujer difiere en función de varios factores: recursos y recompensas, participación en el proceso productivo, presencia de un ordenamiento jerárquico de los roles sexuales en la division del trabajo, lugar ocupado en la organización/institución, lugar en la reproducción de la esfera familiar y en las interacciones y negociaciones de papeles.

Palabras clave: Desigualdad y discriminación, género y clase, feminismo y marxismo, control de la mujer, poder femenino y emancipación.

\footnotetext{
${ }^{1}$ Este texto reproduce un capítulo de un informe correspondiente a la materia "Solidariedade e Exclusión Social", que pertenece a la Carrera de Licenciatura en Sociología, y que el autor presentó en los exámenes públicos de adscripción dentro del área de Sociología; el informe fue redactado y presentado en el año 2003. Aprovecho para agradecer a la profesora Ana Isabel Blanco García la supervisión de la traducción del portugués al castellano.
} 


\begin{abstract}
Despite the relative advance, in legal and political terms, of the defence of egalitarian principles within the relation between men and women, recent (inter)national studies confirm the persisting social borders and inequalities of gender in many contexts (work, daily interactions, values and symbolic regulations, institutional frames).

In this paper, after a revisitation, in a synthetic and critical way, of some theoretical paradigms that look to explain these inequalities (vg socio-biological, psychological conceptions, the structural-functional, the Marxist model, the neo-Weberian) we propose an articulation between the concepts of gender and class. This implies a convergence of the Marxist model with the feminist one and, indirectly, a fruitful crossing between (neo)Marxism and Weberianism, being this one also articulated with symbolic interactionism. This is followed by a brief historical retrospective and correlative deconstruction of the essentialist, reifying and legitimating forms of the statu quo.

Finally, with a brief illustration of some of the gender inequalities in Portugal, we outline a hypothesis that states that, beyond the inherent interests to the mechanisms of macro-economic and institutional domination, the control of the feminine labour force and subsequent phenomena of labour segregation and wage discrimination are whether reproduced or countered at different levels: socio-structural, organizational/institutional and interactive. At the micro and meso-social levels, the power of the woman differs in function of variable factors such as: available resources and rewards; participation in the productive process; presence of an hierarchical ranking of sexual roles in the division of labour; place occupied in the organization of the corporation or institution; place in the (re)productive sphere of the family unit; place in the interactions and negotiations of roles.
\end{abstract}

Key words: Gender Inequality and discrimination, class, feminism and marxism, control of the woman, women power and emancipation.

\title{
1. Introducción: problema y perspectivas teóricas
}

Aunque bajo diversas formas y grados, las desigualdades de género han constituido un fenómeno histórico recurrente en diversos tipos de sociedad. En la moderna sociedad capitalista, se han imbricado en los procesos de (re)producción de ésta y en algunos de sus mecanismos políticos e ideológicos, ocultándose casi siempre, 
bajo razones 'naturales', 'biológicas' o (pseudo)'psicológicas'2. Aunque el grado de constreñimento $^{3}$ para explicar las desigualdades de género se mantenga como una cuestión polémica, las desigualdades de género se manifiestan en la disparidad en el acceso y control de recursos, especialmente en las oportunidades y remuneraciones y demás condiciones sociales (González et al., 1992:199 ss), tanto en la vida pública, como en la vida privada (Abbot y Wallace, 1991).

Tal como ha ocurrido en otras sociedades democráticas, Portugal ha conocido una reducción de las desigualdades de género, sobre todo gracias a la acción de los movimientos sociales femenistas y de algunas fuerzas políticas. A pesar de los considerables cambios en las últimas décadas en el sentido del tratamento políticojurídico legal igualitario de hombres y mujeres y de verificarse una notable disminución de desigualdades de género, éstas, sean evaluadas en una perspectiva diacrónica, sean consideradas en un abordaje sincrónico, son aún una realidad actual y operante a varios niveles. Recientes estudios evidencian que las fronteras y desigualdades de género aún persisten en varias vertientes y sectores de la vida social: en los prejuicios y en las evaluaciones negativas de las mujeres en los contextos institucionales y en las interacciones cotidianas; en los sistemas de herencia y matrimonio (O Neill; 1984; Iturra, 1983; Geraldes, 1986; Silva, 1998; Sobral, 1999), así como en los procesos (extra)judiciales de reconocimiento de la paternidad de hijos fuera del matrimonio y en los procesos de separación o divorcio y subsecuente tutela y guardia de los hijos ${ }^{4}$

${ }^{2}$ Cf. Hartman, 1982; Weeks, 1986; Liljestrom, 1986; Amâncio, 1994; Bourdieu, 1998; Crompton, 2003.

${ }^{3}$ Así, mientras para unos autores la familia, así como su composición y la eventual distribución de sus miembros por las diversas profesiones, tareas y demás actividades, serían moldeadas por determinadas instituciones e ineluctables constreñimientos exógenos y endógenos (edad, género, clase, etnia), para otros asistiría a las familias y sus respectivos miembros una relativa capacidad y libertad de tomar decisiones, definir, seleccionar e implementar estrategias conducentes a la obtención de determinados objetivos. Para más desarrollo a este respecto, cf. Silva (1991:79 y ss) y Leandro (2001:51 y ss).

${ }^{4}$ A este respecto, urge una investigación más apurada, dado que, aunque en los procesos de separación, divorcio y tutela o guardia de los hijos se reproducen situaciones asimétricas en detrimento de la mujer, hay situaciones indiciadoras de que, frente a las dificultades emergentes de la 'nueva' relación madre-hijos o padre-hijos y respectivas redes de relaciones pos-divorcio, 
(Machado, 2003; Torres, 2001); en las concepciones sobre lo masculino y lo femenino (Amâncio, 1993 y 1994), en los códigos en torno a la honra-vergüenza (Cutileiro, 1977 y 1988; Silva 2002); en la desigual distribución del poder doméstico (Silva, 1991) y en la violencia doméstica (Dias, 1998); en los modos de residencia y en la división sexual del trabajo y en la sobrecarga de las tareas domésticas (Wall, 1998); en la segmentación sexual de los mercados de trabajo y en las oportunidades de empleo y las remuneraciones (Ferreira, 1993; Marques, 2002); en la desvaloración de las carreras profesionales de las mujeres y su baja participación en los liderazgos y en la vida política (Viegas y Faria, 1999).

En términos globales e históricos, la cuestión a la que nos enfrentamos se podría enunciar del siguiente modo: ¿cómo comprender y explicar el recurrente fenómeno histórico de la dominación masculina en sociedades y Estados básicamente patriarcales, sean esclavistas y despóticos, sean feudales-aristocráticos y capitalistas, sean incluso en sociedades dichas socialistas o que intentaron caminar en la construcción del socialismo? En el ámbito más circunscrito de este texto, ¿cuáles son los factores estructurantes de la reemergencia y reproducción de las desigualdades de género hoy en día?

Diversos han sido los abordajes socio-políticos ante este problema social que ha devenido también un problema sociológico, sobre el cual, como veremos enseguida, han incidido diversas miradas teórico-metodológicas.

\section{Algunas perspectivas teóricas}

Una de las concepciones corrientes acerca de la discriminación sexual se asentaría en una visión sociobiológica, la cual tiende a vehicular la idea preconcebida de que, mientras el hombre sería un ser más activo y agresivo, más predispuesto al combate

pueden verificarse casos manifiestos o latentes de subalternización no solo femenina sino también masculina.

Cuestiones de género, 2008, nº 3, pp. 13/54 
público y al éxito, la mujer detentaría una construcción biológica más pasiva y orientada hacia la procreación y el cuidado de la casa. Tal posición ideológica patriarcal y darwinista-social pretende, en última instancia, justificar el tradicional dominio del más fuerte social y políticamente: el hombre. Si es innegable que ciertos rasgos físicos y fenotipos específicos acompañan de modo altamente indeleble a hombres y mujeres, ellos han dado todavía lugar a representaciones y categorizaciones que no tienen fundamento, a no ser como modos de legitimación y dominación masculinas. O sea, a partir del diferente fenotipo sexual -que no puede ser negado o subevaluado-, se acentúan de modo sutil determinados arquetipos binarios (exterior/interior, seco/húmedo, cultural/natural) y determinadas dicotomías tales como el dominio de la esfera pública o formal detentado por el hombre frente al reducto privado, informal o doméstico de la mujer, la emotividad espontánea y natural femenina ante la vertiente racionalizante y cultivada masculina, reproduciendo la categorización binaria mujernatural-afectivo versus hombre-cultural-racional. Estas dicotomías son hoy cada vez más reecuacionadas y deconstruidas en la medida en que buscan legitimar los poderes patriarcales en la sociedad, compartimentando lo formal y lo informal, sobrevalorando la esfera pública en detrimento de la doméstica tenida por periférica y banal, en fin, revalorizando lo masculino como el cuadro universal y primordial de referencia y desvalorizando lo femenino como elemento particular, secundario, derivado. ${ }^{5}$

Paralelamente a las justificaciones legitimadoras a través del (pseudo)argumento biológico, importa referir, sobre todo en países de fuerte implantación católica, la función política e ideológica ejercida por la Iglesia Católica, la cual ha convivido secularmente con la defensa de la ética y de la moral patricéntrica o incluso patriarcal, empezando por la máxima de S. Pablo: "Mujeres, obedeced a

\footnotetext{
${ }^{5}$ Cf. Dubisch (1986:7,24), Héritier (1989: 17 y ss), Amâncio (1993,1994), Silva (1999). Como ilustrativo de este tipo de pensamiento véase, por ejemplo, la metáfora bíblica de la formación de la mujer a partir de una costilla del hombre. Para mayor desarrollo de estas categorizaciones y representaciones binarias no sólo diferenciadas como asimétricamente construidas en base jerárquica y desigual, cf. especialmente Costa (1992: 119), Amancio (1993: 130 y ss), Silva, Machado y S. Silva (2002).
} 
vuestros maridos".

Otra explicación (pseudo)teórica, a menudo aducida, se asienta en una línea de interpretación freudiana, según la cual las diferencias de género se centrarían, al fin y al cabo, en la posesión o en la ausencia del pene. En la perspectiva libertaria de Freud (1975), el núcleo verdadero y auténtico de la personalidad humana residiría en el inconsciente (id), o sea, en el instinto libidinal que, en cuanto pulsión de vida y principio del placer, estaría en confrontación con el superego, el cual, con sus normas y valores culturales restrictivos, constituiría el principio de la realidad limitativo de la realización del placer, sublimándose, como mucho, en la creación artística o cultural. El predominio del principio de la realidad con todo el acervo de normas represivas comportaría la negación del eros, del instinto libidinoso, en cuanto principio del placer. Si los chicos serían inducidos a recalcar sus impulsos libidinosos hacia la madre, las niñas serían constreñidas a refrenar su tendencia erótica hacia el padre y a identificarse con la madre.

A la concepción freudiana han reaccionado, y con razón, diversas feministas para quienes la identificación y la construcción del género no implica sólo una realidad biológica -que, finalmente, no se reduce a los órganos genitales ni se concentra tan solo en la fase de Edipo-, sino que envuelve una construcción social en la cual intervienen varias componentes no biológicas. Y, en relación a la propia masculinidad, ésta, adquirida a expensas de la separación de la madre, implicaría no un valor acrecentado sino, sobre todo, una pérdida emocional marcante.

Otra variante psicológica consiste en explicar la génesis y el desarrollo de la identidad y de los comportamientos masculinos y femeninos por los contextos de socialización familiar y escolar con sus respectivos códigos normativos masculinos y femeninos.

A su vez, también la sociología se ha ocupado de esta cuestión, aunque con interpretaciones diferentes. En la óptica estructural-funcionalista, en una versión más elaborada y de cariz predominantemente axio-normativo, las diferencias biológicas y anatómicas de los órganos sexuales masculinos y femeninos son convertidas y erigidas 
en elemento constituyente de las diferencias de género, pretendiendo así justificar ideológicamente la dominación masculina. Pertenece a la concepción estructuralfuncional (Parsons, 1956) en torno de la familia la vieja y recurrente distinción entre la función instrumental llevada a cabo por el hombre, tradicionalmente considerado el sustentador de la familia, y la función expresiva ejercida por la mujer en el ámbito doméstico, vista como el polo afectivo-emocional dedicado al cuidado del hogar.

Evaluando, aunque brevemente, esta visión, de ella se puede inferir una dimensión fuertemente ideológica en la medida en que ella ha reforzado y realimentado concepciones conservadoras e incluso retrógradas sobre la familia: la mujer, vista como 'dueña de casa' y 'servidora del hogar', 'protegida' por la autoridad masculina, manteniendo la función de cuidar material y afectivamente del marido y de los hijos y quedando, en la práctica, alejada de los procesos de trabajo extradomésticos y de participación social y política en la esfera pública.

A las visiones estructural-funcionalistas, que tienden a atribuir al sistema el diferenciado conjunto de roles masculinos y femeninos, se contraponen las perspectivas interaccionistas y simbólico-valorativas (Goffman, 1974) que intentan traer a primer plano no los invisibles constreñimientos estructurales sino más bien la presencia de los actores sociales, ora masculinos ora femeninos, sus recíprocas interacciones, la negociación de los papeles, la participación de las experiencias y vivencias, las cuales son decisivas para definir y construir la propia identidad, sea masculina o femenina.

Otros(as) por su parte, subrayan la importancia del modelo organizacional y de poder en el que los hombres, detentando los mecanismos del poder en varios niveles e instituciones desde las centrales a las locales y familiares, tienden a perpetuarse en las instancias de decisión en perjuicio de las mujeres que detentan, en consecuencia, un rol subordinado: en casa, en la escuela, en el trabajo, en la vida política, posición esta compartida por una considerable parte de las femenistas (Roberts, 1984). Esta línea explicativa nos remite básicamente a la concepción weberiana centrada en el análisis de las relaciones de autoridad y poder en el seno de los grupos domésticos y su articulación con la organización societal y la configuración de los diversos grupos sociales (Weber 
1978:359, 365 y ss). Weber (1978) subraya, con respecto a la formación de la institución familiar, como un lugar de regulación política y económica en torno al patrimonio bajo la orientación del patriarca, que implica un control sobre el patrimonio y la sexualidad femeninas. Esta posición es también suscrita por Segalen (1980:60 y ss), Flandrin (1984:8 y ss) y sobre todo por Bourdieu (1972:1120, 1980:238, 320 y ss), según el cual las relaciones de autoridad y poder en el interior de las familias presuponen la existencia de una competitividad generadora de tensiones y conflictos que amenazan la unidad y la cohesión domésticas. ${ }^{6}$ Sin embargo, en el ámbito del modelo de poder, el autor que representó un especial soporte para las propias teorías femenistas ha sido con mucho Foucault (1994) que muestra cómo operan, a nivel infraestatal, comunitario y doméstico, los mecanismos de poder casi invisibles pero eficientes.

La posición marxista ha asumido tradicionalmente que las asimetrías sexuales se deben básicamente a las desigualdades de clase y, en el mundo de hoy, al sistema capitalista. A la desigualdad sexual subyace la división sexual del trabajo como una de las formas de la división social del trabajo, la cual, aunque en formas variables en

\footnotetext{
${ }^{6}$ Esta cuestión se relaciona con la discusión en torno del carácter patricéntrico/patriarcal o matricéntrico/matriarcal de las sociedades tradicionales sobre todo agrarias. En relación al espacio luso-galaico, más allá de las legitimaciones de carácter biologista y las retroproyecciones ideológicas sin fundamento histórico, no hay unanimidad entre los investigadores sociales. Algunos autores como Geraldes (1987:469 y ss) e Iturra (1983:91 y ss, 1988:103 y ss), aduciendo respectivamente la tónica androcéntrica en las prescriciones legales y sobretodo en las prácticas sociales del comportamiento sumiso, respetuoso y, a veces, deferente de la mujer ante el marido (tratándolo, por ejemplo, de "usted" o "senõr"), han subrayado como trazo dominante la autoridad masculina o incluso patriarcal en casas campesinas en el Miño y en Galicia. En un polo opuesto, autores como Descamps (1935:84,191 y ss, 273,459 y ss) y Willems (1963:70 y ss), con base en observaciones etnográficas de tipo monográfico $\mathrm{y}$, por otro, más recientemente, Santo (1980:18,78 y ss), apelando a argumentos de tipo psicoanalítico en la variante del 'inconsciente colectivo' de Jung, reconocen el poder patriarcal pero subrayan o subliman la telúrica matricentralidad de las relaciones sociales, en especial en el Miño. Por fin, Cabral (1989:109 y ss), basándose en argumentos de tipo simbólico-valorativo y lingüístico-cognitivo-interactivo (por ejemplo, designación de 'patrona' por el marido hacia la mujer), mantiene sobre el poder conyugal una problemática ambigüedad, posición compartida también por Brettel (1991:26) que, en el ámbito del análisis de la dinámica de los movimientos demográficos y migratorios en un pueblo del Miño, subraya bien la patricentralidad, bien la matricentralidad de los grupos domésticos de la zona.
} 
consonancia con el modo de producción dominante, constituye la base de la explicación de las desigualdades sociales incluso de las desigualdades de género. ${ }^{7}$ Hay, sin embargo, que destacar entre los fundadores del marxismo el avance de algunos elementos teóricos relevantes en torno a la división sexual del trabajo y, en particular, la dimensión histórica en relación al origen y a la evolución de la explotación y dominación de la mujer que, según Engels (1980), se relacionaría, a su vez, con el origen de la propiedad privada y del Estado.

A nivel programático y político, para las organizaciones de inspiración marxista, sin excluir propuestas realistas de reformas e incluso sin dejar de presentar iniciativas progresistas con propuestas relevantes para la mejora de la situación de la mujer, la solución estratégica de este problema pasará todavía por el cambio radical de la propia estructura social y por la emancipación de las clases trabajadoras.

En un campo de intersección de la sociología marxista y del psicoanálisis freudiano, importa tambien resaltar la contribución relevante de la teoría crítica de la Escuela de Franckfurt desde Adorno et al. (1950) a Reich (1972) y Marcuse (1963), los cuales, estableciendo un puente entre la dialéctica hegeliana, el marxismo y el freudismo identificaron el superego freudiano con las normas y los valores alienantes del sistema capitalista y explicaron los procesos de dominación por el uso recurrente del concepto de eros, creando así, en los términos de Marcuse (1968), el "hombre unidimensional".

En cuanto a los abordajes feministas, importa diferenciar varias tendencias desde el femenismo liberal que se sitúa en una óptica jurídico-política hasta el femenismo radical que, rechazando la perspectiva marxista en torno al concepto prioritario de explotación/dominación de clase, sostiene como primer elemento explicativo de la diferenciación sexual el concepto central del género y de las

\footnotetext{
${ }^{7}$ También Lévi-Strauss (1977:30 y ss) destaca que la división sexual del trabajo, aunque variable conforme los tiempos y espacios societales, constituye un trazo universal que contribuye a explicar el matrimonio y sus diversas modalidades, lo que implica necesariamente, en mayor o menor extensión, como prerrequisito de cualquier organización social, la prohibición de incesto entre parientes próximos y, consecuentemente, la permuta exogámica de mujeres.
} 
correspondientes contradicciones socio-históricas centradas en la dominación y, eventualmente, en la explotación de la mujer por parte del hombre con toda la serie de representaciones y estereotipos socialmente construidos.

Prestando una particular atención al debate entre marxistas y femenistas y, en el seno de éstas, entre marxistas-femenistas y feministas-no marxistas, importa empezar por hacer referencia al hecho de que la tradicional visión marxista, habiéndose focalizado demasiado en la producción, sea de objetos, sea de seres de la especie humana, suscitó diversas críticas, particularmente de la parte de la teoría femenista que trasladó el acento tónico hacia la familia como la institución nuclear de la reproducción social, la cual, a la par o en articulación con otras instancias, crearía los mecanismos de soporte propiciadores de las condiciones específicas necesarias para la producción dentro y fuera de la casa.

Si es cierto que el proceso de industrialización y urbanización vino a separar el lugar de residencia y el lugar de la profesión extradoméstica, por lo menos para la mayoría de los miembros activos de la familia el trabajo doméstico no pagado, predominantemente ejercido por la mujer, ha constituido en la división social y sexual del trabajo, aunque con variadas funciones conforme el tiempo y el contexto espacial, una condición indispensable del propio trabajo ejercido por el hombre y, en particular, en el ámbito del modo de producción capitalista, una base imprescindible para la acumulación y la expansión del capital, tal como lo acentuaron y desarrollaron diversas autoras sobre todo femenistas de inspiración marxista. ${ }^{8}$ Sin embargo, la tradicional posición marxista no asumía el trabajo doméstico como tema central del análisis de dominación de género ni siquiera lo articulaba adecuadamente con la problemática de la explotación de clase a nivel global, considerando como improductivo el trabajo doméstico, o integrando, como mucho, la intermitencia del trabajo doméstico y/o del

${ }^{8}$ Cf., entre outros, Zaretsky (1973) Meillassoux (1977), Ferreira (1981:48 y ss), Wallerstein (1984), J. Brenner y B. Laslett (1986:116 y ss), Liljestrom (1986:144). Esta idea-fuerza ha sido ampliamente desarrollada por diversos autores marxistas al analizar la articulación entre diversos modos de producción en el processo de acumulación y expansión del capitalismo. 
trabajo asalariado femenino en el ámbito de la teoría marxista sobre el ejército industrial de reserva. Otros, todavía, como Braverman (1974) han avanzado la hipótesis de que la tendencia de descalificación del trabajo afectaba, de modo particular, a la fuerza de trabajo femenina. Otras como Brown (1970) y Ortner (1988), con una fuerte orientación femenista, asumían que la explicación básica de la dominación masculina residiría en el hecho de que la mujer habría sido confinada a los roles domésticos principalmente en torno a las funciones de maternidad.

Dada la insuficiencia de la interpretación marxista dominante, el feminismo radical, desarrollado sobre todo a partir de los años setenta, vino a sostener que la contradicción básica de las desigualdades sociales residía analíticamente no en la contradicción de clases sino antes en la contradicción de género, destacando así la dominación patriarcal de la mujer a lo largo de la historia hasta hoy. Para las feministas radicales no marxistas la relación de dominación y/o explotación patriarcal es transversal a los varios modos de producción e, incluso en relación al capitalismo, presenta una lógica y una dinámica autónomas asentadas ora en las diferencias sexuales biológicas y reproductoras (Firestone, 1976:20 y ss), ora en la específica dominación patriarcal en las relaciones públicas y privadas (Walby, 1997). Esta contradicción hombre-mujer sería por sí sola suficiente para dar cuenta de las múltiples y complejas formas de dominación en varios tipos de sociedades, explicando incluso la oposición de los hombres en las organizaciones sindicales tradicionales, a limitar la competencia de las mujeres en los mercados de trabajo.

Cada vez más, en la actualidad, la línea más fecunda para superar las contradicciones de clase y de género, será una vez más la perspectiva marxista y weberiana. Es, en esta línea que Roberts (1984) y Hartman (1982), cruzando varias influencias desde la weberiana a la marxista, sostienen que el poder de la mujer varía en función del grado de disposición sobre recursos y recompensas, del modo y medida en que participan en el proceso productivo, del grado de movilidad y presencia/ausencia de jerarquización de papeles sexuales en la división del trabajo, siendo esta última variable un factor que, al ser integrado en la teoría de las desigualdades sociales, exige, según 
Garnsey (1982:427), una reconceptualización de las teorías de la estratificación y de las clases sociales.

\section{Poderes y representaciones sobre la sexualidad: breve retrospectiva histórica}

Hasta los años setenta, particularmente en los medios rurales, la sexualidad era un tema tabú, en la antropología y en la sociología era un asunto marginal y prescindible o, cuando mucho, su tratamiento surgía subsumido como un asunto 'desviante' en el ámbito del parentesco, de la familia y del matrimonio. Un paso más para la comprensión de las diferentes interpretaciones más arriba delineadas exige que hagamos un esfuerzo conceptual en el sentido de definir la sexualidad, sobre la cual no hay unanimidad.

El fenotipo sexual, constituyendo una base de diferenciación biológica entre hombres y mujeres, sirvió simultáneamente durante siglos como justificación ideológica de desigualdades sexuales. Sin embargo, las legitimaciones o argumentaciones han diferido considerablemente. Así, mientras en los círculos conservadores tópicos como sexualidad, prostitución, homosexualidad o eran tabús o eran descalificados y marginados por la religión dominante en cada contexto espacio-temporal - en Portugal por la religión católica -, en las esferas ora liberales ora emancipatorias el continente de la sexualidad era objeto de interpretaciones bio-genéticas y psicológicas, en particular por el psicoanálisis de inspiración freudiana o junguiana.

$\mathrm{Si}$, en una óptica organicista, funcionalista y conservadora, la sexualidad era vista como un fuerte impulso carnal que, derivando de energías biológicas instintivas e innatas, debería ser controlada, para evitar sus efectos destructivos y amenazadores de la moral y del orden social vigente, ya en una perspectiva libertaria, la sexualidad, en cuanto fuerza libidinal irresistible, debería irrumpir contra el represivo sistema normativo dominante, no sólo presente en las sociedades tradicionales, sino también en la moderna civilización victoriana, puritana (Millet, 1974). En ambos casos, la sexualidad era conceptualizada de modo esencialista como una fuerza biogenética imparable, próxima a la naturaleza animal y, si no anticultural, por lo menos, metasocial 
y transcultural. Por un lado, en la versión tradicional de la mayor parte de las religiones especialmente de la católica, la sexualidad, inherente al cuerpo y embebida en la 'degradada' condición terrena del ser humano, sólo podía ser vencida por la fuerza del espíritu o tolerada como mal menor por el sacramento del matrimonio, destinado a santificar la relación conyugal y la propia familia. La necesidad de control y domesticación de la sexualidad, en particular de la femenina, conoció varias formas y expresiones, desde la mortificación del cuerpo en la defensa de las superiores virtudes de la castidad y de la virgindad, pasando por las prácticas monogámicas, hasta la posesión y vigilancia de la honra femenina a través del control de la propiedad fundiaria en la herencia y en el modelo patriarcal de matrimonio.

Sin menospreciar las valiosas contribuciones de diversos autores, sobre todo de parte de Freud (1975) y sus seguidores, hay que reconocer que la esencialización naturalizada de la sexualidad y otros fenómenos con ella relacionados vendrían a ser deconstruidos por sociólogos, antropólogos, historiadores y otros científicos sociales que empezaron a definir la sexualidad no sólo como un atributo o propiedad de orden biogenético o psíquico sino como un producto social o, como diría Foucault (1994), un constructo histórico comprensible en su contexto socio-político. La sexualidad es, según el autor, justamente uno de los campos donde los diversos poderes, principalmente los institucionales se ejercen, sea de forma coercitiva e impositiva, sea de modo sutil, subrepticio, casi invisible, pero extremamente eficaz. Siendo el sexismo resultante de las relaciones de poder en la perspectiva foucaultiana, es comprensible que el movimiento feminista haya asumido, como referencia, el pensamiento de este autor como uno de los fundamentos de su posicionamiento ante la sociedad patriarcal, concibiendo así la esfera de las relaciones privadas o (inter)personales de género como una de las expresiones de las relaciones de poder.

La diferencia biológica y anatómica de los órganos sexuales masculinos y femeninos pasó de ser un elemento constituyente de la sexualidad a una justificación ideológica de la dominación masculina, como veremos más adelante. Sin negar los 'imperativos', las potencialidades biogenéticas y psíquicas, los deseos y las emociones, 
después de todo posibilitadoras y, como norma, siempre presentes en la actividad sexual, importa subrayar, como lo hacen Weeks (1986:15 y ss) y Nencel (1994), que la sexualidad no puede ser abordada como una especie de energía bio-psíquica tan solo derivada de genes, hormonas, instintos o del inconsciente y, como tal, 'naturalizada' y desligada del contexto social y histórico. Ella engloba un conjunto de posibilidades biológicas y mentales (identidad de género, diferencias corporales, capacidad reproductiva, necesidades, deseos, fantasías, emociones, valores), que no necesitan estar todas ligadas y, en ciertas culturas, no lo están. Por eso, contrariamente a un abordaje fixista, determinista y reduccionista de cariz ora biogenético ora psíquico, la sexualidad comporta varias dimensiones que hacen de cualquier relación sexual una relación social que, como cualquier otra, es socialmente condicionada, estructurada y construída, para usar la teorización de Luhman (1982), en diversos niveles: socio-estructural, organizacional e interactivo.

Para entender la sexualidad y la mirada diversa dada al comportamiento sexual de los hombres y de las mujeres concretamente en el medio rural, hay que partir de la vertiente socio-estructural, o, sea, de la condición objetiva de vida de los respectivos grupos de pertenencia de las mujeres -lo que engloba la clase social, el género, la edad y demás recursos- $\mathrm{y}$, en seguida, articularla con otros niveles, a saber, el políticoorganizacional en el seno de la comunidad y de la casa y, por fin, el interactivo, el cual toca las propias vivencias, experiencias y sociabilidades en el seno de cada género y entre los miembros de los géneros masculino y femenino. Contrariamente a autores que, de una u otra forma, esencializan y proyectan, sea sobre los hombres, sea sobre las mujeres, determinadas características o atributos de cariz biogenético, psicológico o socio-moral y cultural, importa, teniendo en cuenta estas vertientes, resaltar el proceso relacional que, en determinado contexto histórico en términos socio-económicos, políticos, culturales, permite comprender y explicar los comportamientos sexuales entre personas del mismo sexo o de sexo opuesto.

A nivel organizacional y político-administrativo, el mayor o menor grado de interferencia institucional -eclesiástica y civil-, la mayor o menor dosis de represión 
patriarcal y administrativa con las más variadas prohibiciones y tabús, en particular sobre las mujeres, es dependiente del tipo de sociedad y su contexto espacio-temporal, de las mentalidades, doctrinas e ideologías de la época, sobre todo al nivel institucional y estatal, en relación a los comportamientos sexuales humanos. Varios autores, entre los cuales estarían Flandrin (1983) y Goody (1983), demostraron que los orígenes de la moral sexual occidental se remontan a la cultura judeo-cristiana, fundada en el mito en torno de Adán y Eva (superioridad del hombre, seducido y forzado a trabajar y sostener la prole, inferioridad de la mujer, seductora pero destinada a la función reproductiva) y refundada en los orígenes del moralismo cristiano, sobre todo entre los siglos VI y XI, cuyos mentores eclesiásticos determinaban ciertos interdictos o períodos de continencias sexuales en especial sobre los días, las circunstancias y las formas de cópula conyugal ${ }^{9}$. Para los moralistas cristianos de esta época -cuyas reminiscencias eran visibles aún en los pueblos del noroeste portugués sobre todo hasta a los años setenta (Silva y Van Toor 1988; Silva 1998)- se imponía que el espíritu venciese la carne lasciva. Por eso, además de exaltada la abstinencia por la castidad del celibato, los placeres sexuales eran condenados como comportamientos lujuriosos, salvajes, irracionales incluso en el ámbito del matrimonio. La pasión era peligrosa para el hombre

\footnotetext{
${ }^{9}$ No tener relaciones sexuales durante ciertos períodos (cuaresma, fiestas tales como Navidad y Pascua), ni durante el embarazo, pues esta transgresión, contrariamente al ejemplar comportamiento de los animales, representaría, según S. Ambrosio y S. Juan Crisóstomo, la profanación del trabajo de la creación divina en las entrañas de la mujer (Flandrin 1983:84-85). Y, en cuanto al modo de relacionarse sexualmente, era vedado hacerlo por la retaguardia de la mujer y se imponía que las relaciones sexuales fuesen hechas "con juicio" y sin pasión, tal como advertía S. Jerónimo: : "El hombre sabio debe amar a su mujer con juicio, no con pasión. Que él controle el ímpetu de la voluptuosidad y no se deje llevar precipitadamente a la cópula. No hay nada más infame que amar una esposa como una amante... Adúltero es también el marido demasiado apasionado por su mujer... En relación a la esposa de otro, en efecto, todo el amor es vergonzoso; en relación a la propia, el amor es excesivo" (Flandrin 1983:116). Cf. también M. Almeida (2000:75-81).

Según Flandrin (1983:69 ss), estas prohibiciones, más allá de la glorificación del celibato y de la esterilidad por diversos padres-santos de la Iglesia Católica (S. Agostinho, S. Gregório de Nisa, S. Ambrósio, S. Jerónimo, S. Basílio, S. João Crisóstomo) podrían, si fueran rigurosamente observadas, poner en peligro el equilibrio demográfico de la Alta Edad Media, aun cuando sus responsables no tuiviesen de eso conciencia.
} 
y para la sociedad, pues, si fornicar fuera del matrimonio era un pecado muy grave, tambien grave era hacerlo con pasión ardiente con la propia mujer. Mas, no sólo la mujer era portadora de 'inmundas' impurezas (vg. la sangre menstrual), sino que también el propio coito era fuente de impureza y, por eso, se cuestionaba incluso si la mujer grávida, debido no tanto a la fecundidad sino al acto sexual que la provocó, podría ser bautizada (Flandrin 1983:87 y ss, 99-100, 116-124). La sexualidad, por lo tanto, era tan solo admitida, como 'útil' a la sociedad, para la procreación y, como tal, debería ser regulada, controlada, domesticada. Si, como refiere Goody (1983), desde el siglo $\mathrm{V}$ hasta la emergencia de la modernidad $-\mathrm{y}$ en sociedades agrarias como la portuguesa probablemente hasta a los años setenta del siglo XX- la Iglesia ha constituido la principal institución modeladora de las reglas y normas relativas al matrimonio, ella vendrá progresivamente a ser sustituída en esa función pero de forma laica por el emergente Estado-Nación que, desde los siglos XVIII y sobretodo XIX, vino ganando un creciente poder de regulación.

Es teniendo en cuenta el fondo de la doctrina judeo-cristiana como es posible comprender de qué manera determinadas conductas son consideradas normales, aceptables y otras desclasificadas como anormales, desviadas o incluso patológicas, un supuesto que nos remite a las concepciones funcionalistas de modo especial a las durkheimianas acerca de los hechos sociales normales y patológicos. De hecho, a este respecto, el propio Durkheim (1974) dejaba de ser el sociólogo que pretendía explicar lo social por lo social para caer en la armadilla filosófica esencialista, al asumir que el hombre, así como la mujer, siendo 'por naturaleza' libertinos o poseyendo apetitos desenfrenados principalmente los sexuales, carecían de alguna forma de control y regulación. Por eso, según Durkheim (1977), si la religión y las diferentes comunidades eclesiásticas sobre todo la católica, constituían en las sociedades agrarias tradicionales $\mathrm{y}$, en articulación con Estados de cariz conservador ${ }^{10}$, las principales instituciones

\footnotetext{
${ }^{10}$ De modo alguno se pretende asociar a Durkheim (1983) a posicionamientos próximos de regímenes corporativos totalitarios o fascizantes -es bien conocido su empeño en el sistema democrático entonces vigente y la insistencia en las fórmulas educativas por la persuasión y no
} 
reguladoras de fenómenos 'desviantes' o 'patológicos', en las sociedades modernas tendrían que ser, a la par de la familia, de la escuela y de los cuerpos profesionales intermedios de los propios ciudadanos, las instituciones públicas estatales que, directamente o a través de cuerpos profesionales tales como el policial, el judicial y el médico, deberían regular y controlar el amplio campo biosocial y político de la sexualidad. $^{11}$

Las pautas de comportamento sexual inculcadas en los procesos de socialización, son, en consecuencia, diferentes por sexo: en cuanto las mujeres son educadas en el sentido de asociar la actividad sexual a la intimidad emocional, los hombres son inducidos a disociar dicho impulso sexual y la emoción, suscitando en ellos diferentes representaciones y significados de la feminidad: desde la mujer como objeto de placer, asociado a la hembra animal con una sexualidad potencialmente transgresiva y disruptiva, pasando, a veces, por arquetipos (vg. 'mujer-serpiente') y estereotipos (la 'mujer-puta'), hasta la figura virtuosa y protectora de 'esposa' y 'madre', paradójicamente asexuada y sublimada como fuente de vida (vg. la procreación, la leche materna). Tal como ya lo hiciera Segalen (1983) para el contexto rural francés, tales códigos morales y culturales habrán necesariamente de ser articulados con la propia estructura social y económica de las sociedades agrarias de modo especial mediterráneas $\mathrm{y}$, en particular, con la correlativa necesidad de

por la represión. Cabe, sin embargo, referir que el corporativismo durkheimiano presenta curiosas semejanzas con la doctrina social de la Iglesia, también ella compartida, en línea de principio, por Salazar. Sin embargo, el corporativismo centralista inherente al régimen dictatorial salazarista lo alejó, en términos teórico-prácticos, del corporativismo de asociación idealistamente propugnado por algunos disidentes internos del Estado Novo como, por ejemplo, Castro Fernandes (Wiarda, 1977).

${ }^{11}$ Con la emergencia de enfermedades sexualmente transmisibles (ayer enfermedades venéreas como la sífilis, hoy otras mortales como el SIDA), la necesidad de regulación y control se vuelven bien razón, bien pretexto cada vez más imperativo en relación al control de las sexualidades alternativas llamadas "desviantes", "artificiales", "anormales" (vg. uniones de hecho, homosexualidad...) y, en particular, con la sexualidad mercantilizada como es la prostitución. Aunque en moldes y latitudes diferentes, y con medios más sofisticados que en el pasado, la política sexual se halla también hoy en el centro de las políticas de salud pública, especialmente en torno al fenómeno de la prostitución (Silva, 1998; Machado, 1999; Ribeiro y Sacramento, 2002). 
preservación del patrimonio fundiario, como lo subraya J. Schneider (1971) y, por fin pero no menos importante, con el dominante carácter patricéntrico en las casas de estas comunidades. $^{12}$

Los resultados de varios estudios, constatando una competición interna entre marido y mujer por el control del poder doméstico, habrán de ser comprendidos y explicados, sea a partir del volumen de $\operatorname{recursos}^{13}$ que cada parte trae consigo hacia el matrimonio y/o adquiere durante la vigencia del mismo, sea sobre todo debido a los mecanismos tradicionales de subordinación política e ideológica femenina. Entre estos cabe especial referencia el designado binomio cultural honra-vergüenza que, en la base de ciertos atributos de orden sexual, presupone como interdependientes y complementarios roles y funciones sociales, económica y políticamente desiguales entre hombres y mujeres.

A lo largo del tiempo se han reproducido y legitimado éstas y otras normas y valores estereotipados acerca del comportamiento masculino y femenino: el hombre como elemento activo y asertivo, desde el punto de vista social, profesional y sexual; la mujer como el elemento pasivo, con un papel restringido a la esfera doméstica, a quien el binomio honra-vergüenza ${ }^{14}$ es evaluado y aplicado de modo negativo y defensivo

\footnotetext{
12 Algunos resultados obtenidos de la propia investigación en Aguiar, en el municipio de Barcelos, muestran que, a la par de un $30.8 \%$ de casos de dominación masculina y $37.5 \%$ de relativo equilibrio más o menos inestable pero negociado, solo en el $8.6 \%$ de las casas era, de hecho, la mujer quien comandaba los destinos del hogar (Silva, 1991:87).

${ }^{13}$ Para definir el poder doméstico importa tener presente, además del lugar de residencia, la composición de los grupos domésticos y las interacciones conyugales, el concepto de recursos materiales y simbólicos en términos amplios: bienes patrimoniales, atributos estéticos y eróticos, experiencia y fuerza física, habilidades, saberes y calificaciones, honra, prestigio y poder local, utilización del espacio y del tiempo, entre otros.

${ }^{14}$ Honra y verguenza son conceptos correlativos, bien en una perspectiva colectiva, bien en un abordaje individual, pero ambos en un ámbito tradicional, conservador. La honra y la honradez, aunque vistas como atributos colectivos de ciertas sociedades mediterráneas, necesitan ser reactivadas y dependen de la voluntad de los miembros de la familia y, en particular, del hombre. El propio concepto de honra presupone la posesión no sólo de bienes a defender como de atributos, valores y virtudes apreciadas en un "verdadero hombre", en un "hombre viril", adulto, por regla casado, que se respeta y hace respetar, sino tmabién es necesario por la confrontación física, por su lealtad y equidad, por su generosidad y colaboración en la comunidad, que se responsabiliza del sustento y de la protección de la familia y se enorgullece de su reputación
} 
(tabús, prohibiciones, defensa de la virginidad). En las pautas tradicionales de socialización entre chicos y chicas las imágenes construidas sobre la mujer como criatura subordinada, sexualmente insaciable y peligrosa y, por lo tanto, carente de protección para mantenerse casta y virgen antes del matrimonio, así como la asunción del rol de recatada esposa y madre de hijos, orientada hacia el interior de la casa, servían efectivamente al orden social vigente $y$, en particular, al poder masculino. Así, mientras los 'desvíos' o 'aventuras' masculinas en materia de comportamiento sexual, además de justificadas por la 'impulsividad natural' masculina, no afectaban la honradez del hombre-'prevaricador', pudiendo incluso ser objeto de encomio, la mujer, transgrediendo, quedaba indeleblemente marcada, emocional y económicamente sobrecargada en la comunidad, en especial siempre que surgían hijos ilegítimos de relaciones sexuales no convencionales u oficialmente aprobadas. Del mismo modo, mientras al chico le era tolerada, estimulada e incluso premiada cualquier aventura sexual extravagante y atrevida, a la mujer le era recomendada o hasta impuesta la contención sexual, siéndole refrenados y reprimidos sus apetitos sexuales no sólo por parte de los padres -los 'empresarios de la moral' en la terminología de Becker (1968)-, sino incluso por parte de la familia y, en particular, de los padres.

Contrariamente a la interpretación culturalista defendida por autores como PittRivers (1988), Peristiany (1988) y, hasta cierto punto, Cabral (1991), el código de honra-vergüenza principalmente en el campo sexual no posee sólo una dimensión cultural sino que es interdependiente y condicionado por otros factores que se ligan, como refiere Cole (1991), con la posición económica y social de la mujer-trabajadora y con la ideologia católica de la dominación y sujección de la mujer por el hombre. A pesar de la pertinencia de la deconstrución teórica e ideológica del binomio cultural

social y éxito profesional. La mujer, para que sea considerada honrada, debe trabajar y gestionar bien la casa, tenerla limpia, cuidar del marido y de los hijos -los cuales deberán andar bien vestidos-, ser recatada y modesta, cumplir com sus obligaciones religiosas, comportarse decentemente, para no perder la honra, en una asociación de conceptos socio-morales que obliga a establecer una especial relación con la esfera sexual ("la pureza sexual") (Pitt-Rivers 1988 y 1997; Peristiany, 1988). 
honra-vergüenza, como lo hace Cole (1991), es importante retener que tal construcción no era sin embargo tan solo ideológica, sino que formaba parte de una realidad económica y social vivenciada en la vida cotidiana de las sociedades rurales, sobre todo mediterráneas, hasta fechas recientes . Por eso, tales códigos culturales no pueden ser eliminados simplemente como espurio factor ideológico en la medida en que tales códigos, aun cuando no totalmente concordantes con la realidad, estaban en ella incorporados. La manutención del código de la honra-vergüenza en la sociedad rural portuguesa, entre otras, ha representado una forma de dominación de los grupos sociales más privilegiados $\mathrm{y}$, en especial, de los hombres de esos grupos sobre sus respectivas mujeres (y, como veremos, enseguida, sobre las mujeres de hombres desposeídos!). Si las mujeres sin recursos fundiarios, cuando eran transgresoras, eran dadas como 'mujeres sin vergüenza', las demás, pudiendo heredar o habiendo heredado bienes patrimoniales, eran obligadas a observar comportamientos sexuales concordantes con su estatus, ora de potenciales candidatas a buenos matrimonios, ora de esposas herederas y conformadas a las normas de los grupos sociales dominantes. A este respecto será interesante subrayar que el principio de la articulación entre honra y posición social es más aplicable a las familias acomodadas, una vez que, en el caso de las familias pobres y asalariadas, éste es, tal como lo refirió Cutileiro (1977), derrogado: las criadas y las mujeres de los trabajadores asalariados, por motivos de dependencia clientelar, podrían tener relaciones sexuales con los patrones de sus maridos, incluso, a menudo, con el conocimiento de estos últimos.

La política sexual reemerge hoy como objeto de disputa y movilización políticas, incluso partidaria, por un lado, entre conservadores restrictivos y hostiles a la educación sexual y a las sexualidades alternativas y, por otro, por los liberales permisivos y practicantes de estas prácticas alternativas, protagonistas de corrientes contestatarias de cariz a veces moderado (socialistas), otras más radical (marxistas y femenistas). Gracias a las luchas y a los movimientos sociales conducidos por estas últimas fuerzas contra las políticas e ideologías conservadoras se han registrado algunos avances en las políticas sexuales, las cuales para unos representan una forma de 
incorporación de esos movimientos y para otros conquistas y plataformas para nuevas reivindicaciones.

\section{Desigualdades de género en Portugal: una breve mirada}

Haciendo una breve retrospectiva, centrada en la sociedad portuguesa hasta los años ochenta y sobre todo hasta 1974 y teniendo en cuenta algunos resultados de estudios realizados por sociólogos, historiadores y antropólogos y otros científicos sociales en relación a la sociedad portuguesa, podemos constatar procesos de dominación patrimonial y masculina sobre mujeres, principalmente en el medio rural: las más privilegiadas desde el punto de vista económico para preservar y reforzar el patrimonio de la casa, las menos dotadas y sobre todo las desposeídas como objeto de dominación de los hombres sobre todo de los originarios de los grupos sociales más privilegiados. Estos procesos de dominación no excluyen con todo la emergencia, aunque de modo latente, informal o 'infrapolítico', de "registros ocultos" (Scott, 1990), denotativos de prácticas y estrategias alternativas y visiones contra-hegemónicas, en este caso por parte de las propias mujeres ('instuiciones' disidentes, 'subversiones' informales). Así, indagando sobre el fenómeno de la ilegitimidad y cuestionando sobre cual la condición, sea de los padres biológicos, sea de las madres solteras, constatamos la desigualdad sexual y el tratamiento social diferenciado y discriminatorio hacia las mujeres, conclusión ésta extraída de varios estudios. Por ejemplo, en Fontelas, nombre ficticio de un pueblo de Trás os Montes, O’ Neill (1984) constató cómo, a lo largo de generaciones, en un sistema de herencia indiviso o aventajado, los padres de los hijos ilegítimos - hasta mediados del siglo XX con porcentajes cerca de los 30\% - eran, por norma, hijos de propietarios-labradores no herederos, mientras las mujeres eran, por regla, jornaleras.

También en el Miño, diversos autores (Geraldes, 1987; Cabral, 1989; Brettel, 1991; Silva, 1998) verificaron, asímismo, desde mediados del siglo XIX, sea en sistemas de herencia aventajados, sea en sistemas de herencia divisa, cómo mujeres 
desposeídas (criadas, jornaleras o campesinas muy pobres) eran madres solteras de hijos ilegítimos -en índices, aunque menores, próximos de los de Trás-os-Montes, sobretodo en el Alto Minho-, cuyos padres biológicos eran, cuando no labradores-propietarios, guardas fiscales y forestales, comerciantes e incluso artesanos y obreros con rentas fijas. En notable contrapunto con los comportamientos tradicionales entre géneros, se podrá decir que la consideración de la dimensión espacial y sobre todo temporal nos permite hoy relativizar o hasta abandonar la rigidez conceptual de los valores centrados en la honra y en la vergüenza. A esto han contribuído decisivamente el éxodo rural y, en particular, la movilidad geo-social de la mujer en dirección a los centros urbanos nacionales o extranjeros, la disolución de las fronteras rural-urbano, el aumento de los niveles de escolaridad, el impacto de los medios de comunicación social y los cambios de mentalidad, factores estos que han inducido a alteraciones en los comportamientos y modos de relación entre hombres y mujeres (Wall y Almeida, 2001). Ya no es así tan fuerte la carga coercitiva del binomio cultural honra-vergüenza sobre la mujer, sea sobre la mujer casada, sea sobre todo la joven soltera. En cuanto a la mujer casada -salvo el caso de eventual adulterio que continúa siendo asunto tabú y severamente reprobado, aunque no siempre necesariamente objeto de ostracismo comunitario-, ya no está sujeta a presiones tan asfixiantes como antes. La mujer frecuenta más el café y otros locales públicos en las villas y ciudades desarrolladas, incluso sin la compañía del marido; se inmiscuye más en la esfera pública en asuntos no sólo religiosos sino también políticos, sobre todo locales. Es, sin embargo, en el comportamiento de la chica soltera donde es posible destilar una visible descompresión del complejo honra-vergüenza y la subsecuente liberación de las tradicionales normas que inhibían o aprisionaban a su congénere de hace treinta años. Recibiendo a menudo, dentro y sobre todo fuera del pueblo, renta propia, ella se permite iniciativas sin el control paterno o fraterno en ciertas salidas, a veces nocturnas, en los fines de semana, a los pueblos circunvecinos y ciudades (fiestas, discotecas, boites), así como, en el propio pueblo, frecuenta cafés y establece relaciones amorosas más libremente sin dar tantas explicaciones a la familia. Por último, en bastantes eventos y ocasiones, ya no hay la rígida separación de división 
de tareas y de espacios como entonces. No sólo cada uno de los sexos asume tareas que eran tradicionalmente atribuídas al sexo opuesto, sino que además fue disminuyendo la antigua separación de espacios, por sexos, en la iglesia, (hombres en la parte de frente, mujeres en la de atrás), en las procesiones y en las tiendas y cafés. Este proceso es todavía lento, constatándose, tal como lo hace notar Santos (1994:87), una considerable discrepancia entre la igualdad formal reconocida en texto legal y las prácticas de asimetría sexual, a empezar por la desigual distribución de tareas domésticas, entendidas en el imaginario tradicional y en las prácticas cotidianas como funciones predominantemente atribuibles a las mujeres. A pesar de que los hombres, sobre todo en las generaciones más jovenes, participan, en mayor medida, en las tareas domésticas, son las mujeres y de lejos las más sobrecargadas con tales tipos de trabajo. En la esfera de la participación pública, sea en la política, sea en los medios de comunicación, las mujeres, aunque están académica y profesionalmente habilitadas, protagonizan, en bastante menor grado, procesos de liderazago y movilización cívica y política (Dinâmia 1997, Viegas e Faria 1999:66).

Los cambios, sea a nivel social y económico, sea, aunque más lentos, al nivel de las mentalidades, van con todo operando en la sociedad. Las mujeres, además de conseguir el reconocimiento de igualdad de tratamiento en términos legales, vienen engrosando las filas de los diversos mercados de trabajo extradomésticos como asalariadas, pasando, en Portugal, del 18\% en 1960 para el 44\% en 1992 (Mendes 1997:130). La elevada tasa de feminización del empleo en Portugal -la tercera mayor de Europa en los escalones de edad de los 25 a los 49 años- se debe a varios factores: necesidad de complementar bajos salarios de los hombres en los agregados domésticos, factores de orden histórico como la importancia de la pequeña agricultura campesina, sobre todo a partir de la eclosión de la guerra colonial y de las oleadas emigratorias a partir de los años sesenta y, por fin pero no menos importante, el proceso, aunque lento, de concienciación de las mujeres de reivindicar un lugar de realización y/o revalorización profesional extradoméstica sobre todo a partir del 25 de Abril y, en 
particular, por parte de mujeres escolarmente calificadas (cf. respectivamente Ferreira, 1999; Cabral, 1997:89).

Además de eso, del estudio de Mendes (1997:144 y ss) se constata que, cuando analizamos la movilidad social de las mujeres no tanto a partir de la situación de clase de los maridos y/o familias de origen sino más bien a partir de la profesión de las propias mujeres, se infiere la existencia de menores obstáculos para la movilidad intergeneracional en especial a partir de la permeabilidad posibilitada por las calificaciones, lo que ha sido visíble por el aumento exponencial de la femenización en el sistema de enseñanza. Aunque porcentualmente en los grados de enseñanza básica y secundaria las mujeres posean tasas de fracaso mayores que los hombres, ellas, sobre todo las mujeres con menos de 35 años, han venido a superar los hombres en la obtención de diplomas de cursos superiores y en varias categorías sociales (cf. Mendes 1997:149).

Transversalmente a varias clases y grupos sociales, afectando todavía más a los asalariados, se deberá apuntar, aunque de modo sucinto, las desigualdades sexuales en la estructura de empleo, en que la mayoría de las mujeres portuguesas, además de conocer una distribución desigual en el mercado de trabajo (41.4\% contra $58.6 \%$ de hombres), ${ }^{15}$ se localiza en las áreas y en las profesiones menos rentables y peor remuneradas. Aunque en menor medida que en otros países europeos, que conocían valores de segregación sexual de la mano de obra por encima del $40 \%$, Ferreira (1993:239) constata en diversos sectores de empleo en Portugal una tasa del 35\%, lo que se debe a una menor tasa de empleo y a una tasa más elevada de trabajadoras autónomas principalmente en la agricultura ( $27 \%$ del total) de la de Europa.

Algunas ocupaciones profesionales tales como la magistratura, la carrera militar, diplomática o empresarial han sido en el pasado vedadas u obstaculizadas a las

\footnotetext{
${ }^{15}$ Hay todavía por estudiar un considerable cambio desde los años sesenta. Si bien el contexto estructural de hace cerca de treinta años era bien diferente, se podrá referir el creciente peso de la población activa femenina que en 1995 es del 41.4\% del total y en 2010 será del 45.5\% (MEPAT, 1998:V-4).
} 
mujeres y, también después del 25 de Abril de 1974, han sido en la práctica dificultadas. La participación política en los gobiernos, más como secretarias de Estado que como ministras, no sobrepasó el 10\%, quedándose entre el 3\% y el 5\% hasta 1981 y, a excepción del XII gobierno constitucional con el 10\% de mujeres, entre el 5\% y el 8\% entre 1981 y 1995 (Viegas y Faria 1999:49-50). A nivel parlamentario, ocurren situaciones semejantes en las que los porcentajes de candidaturas femeninas se sitúan en el orden de los $10 \%$ a $15 \%$, pero los porcentajes de las electas se fijan en una tasa inferior: entre el 4\% y el 11\% a lo largo de cerca de 20 años (Viegas y Faria 1999:54$55)$.

No obstante algunos considerables avances y mejorías en las posiciones relativas de las mujeres, importa retener que, más allá del hecho de la integración en el mercado de trabajo las mujeres padecen un elevado grado de precarización, segmentación e incluso segregación sexual ${ }^{16}$ en ciertos sectores (v.g. textil, enseñanza, seguridad social, agricultura), y existen aún considerables barreras para la inserción y realización profesionales de las mujeres: el menor grado de escolaridad básica y secundaria, al que hay que añadir la insuficiencia de infraestruturas sociales estatales y, en particular, la baja cobertura de la red pública de enseñanza prescolar y sobretodo ATL's (Actividades de Tiempos Libres). Por otro lado, se verifica una subrepresentación de mujeres y un bajo grado de participación en los lugares de dirección en determinados sectores de la vida económica y sobre todo en órganos del poder político (Freire, 1998; Viegas y Faria, 1999), ${ }^{17}$ situaciones de discriminación salarial y -por fin, pero no menos importante- el reparto desigual de las tareas

\footnotetext{
${ }^{16}$ Cf., a este respecto, Ferreira (1993:239 y ss) que distingue entre segregación sexual horizontal o sectorial y la segregación sexual vertical, la cual se relaciona con el nivel de calificaciones y con el bajo índice de empleo en lugares de cuadro y jefatura.

17 En términos de partidos, la subrrepresentación es diferenciada: mayor en el Partido Social Democrata (PSD) o Partido Popular (PP) y menor en el Partido Comunista Português (PCP) o Bloco de Esquerda (BE, Bloco de Izquierda) (Freire 1998:116 y ss). Sucede que incluso cuando la mujer participa en órganos de poder político, especialmente autárquico, le son atribuidas funciones asociadas a la "acción social", "educación y juventud", "cultura", contrariamente a los hombres a los cuales son conferidas las relativas a "obras y urbanismo", "deporte" (cf. Dinâmia, 1997:52), reproduciendo y ampliando así los tradicionales estereotipos del contexto doméstico.
} 
domésticas, así como la sujección a prácticas discriminatorias y no pocas de violencia, denotativas, a su vez, de la frecuente y desigual distribución del poder en favor del hombre y en detrimento de la mujer. Aun cuando las mujeres han conquistado, ya sea a través de movimentaciones sociales, o a pulso en términos individuales, determinados lugares socio-profesioanles, tal ocurre, en este caso en Portugal, gracias a un elevado precio en sobretrabajo doméstico, más allá de eventuales procesos de heteroestigmatización y autoculpabilización de menor dedicación a la familia y, en particular, a los hijos.

\section{Género y clase: por una articulación conceptual pluridimensional}

La tradicional visión marxista, habiéndose focalizado demasiado en la producción, sea de objetos, sea de seres de la especie humana, suscitó diversas críticas, particularmente de la parte de la teoría feminista que dislocó el acento tónico hacia la familia como la institución nuclear de reproducción social, la cual, a la par o en articulación con otras instancias, crearía los mecanismos de soporte propiciadores de las condiciones específicas necesarias para la producción dentro y fuera de la casa.

Avalando las diversas concepciones sobre las desigualdades de género atrás referidas, considero extremamente interesante el debate recurrente entre marxistas y femenistas, proponiendo a este respecto una alianza que, después de los primeros encuentros informales, casi clandestinos, en la lucha práctica cotidiana, conduzca a ecuacionar y articular de modo fecundo el viejo-nuevo problema en torno de la relación entre clase y género.

En primer lugar, está en cuestión la perspectiva tradicional marxista que, al centrarse en el modo de producción, secundarizó o subestimó el proceso de reproducción que, en relación a las cuestiones de género es nuclear, siendo posible fundamentar esta posición a partir de una nueva lectura de los propios escritos de Marx y Engels desde la Ideologia Alemã (1972), pasando por O Capital (Marx 1974) hasta la Origem da família, da propriedad privada e do Estado de Engels (1980), siendo quizá 
en esta última obra donde surge con mayor claridad la centralidad determinante no sólo de la producción sino también de la reproducción social: "De acuerdo con la concepción materialista de la historia, el factor decisivo en la historia es, en última instancia, la producción y la reproducción de la vida inmediata. Todavía esa producción y esa reproducción son de dos tipos: de un lado, la producción de los medios de subsistencia, de productos alimenticios, ropa, habitación e instrumentos necesarios para todo eso; del otro lado, la producción del propio hombre, la producción de la especie" (Engels, 1980:8).

Tal como ocurre en la relación entre el modo de producción capitalista y los demás modos de producción no capitalistas (campesino, artesanal, tributario), en que estos son subsumidos e incorporados por aquel bajo formas de coexistencia subalternizada en función de la necesidad de reprodución y expansión del capitalismo, así también el trabajo doméstico, histórica y usualmente femenino, desempeña un papel crucial en la creación de valor, sirviendo así a los objetivos de producción y de reproducción del sistema. Se trata así de la articulación entre el trabajo asalariado fuera de casa y de las formas de trabajo domésticas no capitalistas utilizadas por el propio modo de producción capitalista, perspectiva ésta que obliga a abandonar la homología dual de que, mientras al hombre pertenecería la esfera de la producción, a la mujer le corresponderían tareas no productivas en la esfera de la reproducción.

El propio concepto de reproducción social aplicado a la economía y a la sociedad comporta inexorablemente, en las esferas de la producción, distribución y consumo, relaciones e intercambios, sea de los seres humanos entre sí, sea de estos con la naturaleza y los ecosistemas envolventes, procesos y relaciones que repercuten en las propias relaciones interfamiliares e intradomésticas. En esta óptica, el proceso de reproducción implica un proceso de producción y viceversa: "Ninguna sociedad puede dejar de consumir, ni puede, por lo tanto, dejar de producir. Por consiguiente, todo proceso social de producción, considerado en sus constantes vínculos y en el flujo ininterrumpido de su renovación, es, al mismo tiempo, un proceso de reproducción" (Marx, 1974:515). 
Para Harris y Young (1981:113) se deberían distinguir tres sentidos de reproducción social en consonancia con la amplitud y el nivel de abstracción implicados: (i) en cuanto reproducción de una determinada sociedad o formación social; (ii) en cuanto reproducción de la fuerza de trabajo; (iii) y en cuanto forma de producción de seres humanos, o sea, de reproducción biológica de la especie. Si esta última constituye una condición necesaria de la reproducción de la formación social, las condiciones y respectivas tasas de reproducción humana no derivan simplemente de la reproducción de la sociedad como un todo. Del mismo modo, la reproducción del trabajo adecuadamente socializado es igualmente condición necesaria pero no suficiente de la reproducción social, por lo que implica a los portadores de relaciones sociales específicas, incluyendo también los no productores. Mientras el concepto de reproducción social en la primera acepción, en términos sistémicos y al nivel más abstracto -también tratado por Marx (1974) al analizar el circuito que atraviesa la reproducción del capital (producción-circulación-consumo-producción)-, presuponiendo o no las relaciones de género, no exige necesariamente la diferenciación hombre-mujer, ya, todavía, en los dos subsecuentes sentidos la inclusión de la discusión sobre el género se vuelve imprescindible, una vez que es no sólo bajo condiciones concretas de dominación y subordinación capitalista de hombres por hombres sino también de género (o sea, de mujeres por hombres y de hombres por hombres en cuanto al control de la circulación/distribución de las mujeres) que la reproducción amplia del capital ocurre y, eventualmente, se intensifica. Consecuentemente, tal premisa exige que, tal como la aplicación de categorías del modo de producción capitalista a modos de producción no capitalistas comporta indebidamente definiciones negativas a las respectivas clases sociales de estos últimos (Silva, 1987), también para dar cuenta de las desigualdades de género, el clásico concepto de clase es insuficiente $\mathrm{y}$, por eso, tendrá que ser recuestionado, reecuacionado y complementado con otras categorías específicas y, en este caso, por categorías asociadas al género. $\mathrm{O}$ sea, los procesos de acceso y control del trabajo en sociedades no capitalistas son codeterminados por otros criterios y no sólo ni sobre todo los del mercado de trabajo sino más bien factores tales como las relaciones 
de parentesco, filiación, edad, control sobre el proceso de circulación, prestigio y otros factores (cf. Meillassoux 1977). Por todo esto, el control sea sobre el trabajo, sea sobre la sexualidad femenina y la capacidad reproductiva de las mujeres, sea incluso sobre la fuerza de trabajo de éstas y de la de sus propios hijos principalmente a través del matrimonio, que difiere de sociedad en sociedad, son todavía aspectos centrales para evaluar la importancia de las relaciones de género para la reproducción social.

Es en esta óptica que Harris y Young (1981:124 y ss), procurando suplir una laguna en la tradición marxista y en la propia antropología en general más ocupada con los mecanismos de transmisión de la propiedad, señalan la importancia de la reproducción del trabajo, la cual, siendo condición sine qua non de la reproducción social, abarca tres aspectos: (i) la alocación y la subsecuente reproducción de los individuos a través de prácticas matrimoniales predominantemente endogámicas en el seno de determinada clase; (ii) la reproducción ideológica del trabajo adecuadamente socializado en determinadas prácticas, normas y valores culturales, lo que es cultivado a partir de las primeras fases del proceso de socialización doméstica y escolar, aspecto este destacado por Bourdieu y Passeron (1977); y (iii) la manutención cotidiana de las condiciones de vida materiales (alimentación, vestuario, 'recreación'), aspectos estos donde, como ya referí, el tradicional trabajo doméstico femenino y las demás condiciones de la estructura de la familia han sido cruciales para los procesos no sólo de reproducción como de producción. Aunque, en cualquiera de estos tres aspectos, la mujer ocupe una posición central, el trabajo doméstico, entendido en una visión androcéntrica como trabajo tan solo reproductivo, subsumido en el llamado sector informal o encuadrable en el citado trabajo comunitario, a menudo considerado de bajo estatuto social e incluso, a veces, no-trabajo, constituye parte integrante, a la par que otros servicios de las políticas sociales, del proceso global de reproducción del trabajo en beneficio del capital.

Como refieren Rapp (1983:34 ss) y Heller (1986), los procesos de reproducción en determinados sectores (vg. campesino, artesanal) tienen lugar simultáneamente no sólo en la esfera productiva extradoméstica, sino también en las 
tareas propiamente domésticas en lo cotidiano, cuya responsabilidad, programación y ejecución acaban, conforme la tradicional ideología en torno del género, por quedar predominantemente a cargo de la mujer. En esta óptica, la ya referida retrógrada y protoburguesa visión (neo)parsoniana en el sentido de fijar la figura femenina como simple y única componente expresiva de la familia en subalterna complementariedad con la componente instrumental masculina, en cuanto recultador de los medios de subsistencia, fue con pertinencia refutada por diversos autores, entre ellos Hareveen (1982:2 y ss, 1976: 190 y ss) y Poster (1979:102). Tal concepción puede ser reveladora del modelo teleológico de las familias de las clases intermedias e incluso asalariadas, pero es flagrantemente denegada y contrariada por la división sexual del trabajo en la época del capitalismo tardío y más aún en las economías y sociedades agrarias o en el contexto de transición hacia el capitalismo. Aquí la mujer, además de heredar y coorientar la casa en términos aproximados a los del marido, es activa en las diversas tareas productivas extradomésticas (cf. Silva 1998:127). Además de eso, las propias tareas estrictamente domésticas, haciendo, directa o indirectamente, parte integrante de los procesos productivos no sólo dentro sino fuera de la casa, crean condiciones necesarias para la continuidad de los procesos productivos extradomésticos en el ámbito de las propias formaciones sociales capitalistas.

La dominación patriarcal y correlativa subordinación de la mujer no es solo ideológica ni siquiera tan solo política sino que se basa en las esferas de producción y de reproducción y, por otro lado, abarca también otras esferas de la vida social, en suma, en las condiciones de vida objetivas - un concepto más amplio que el de clase, como veremos enseguida. Tal como refiere Bourdieu (1998), las diferencias de género son construídas en la base de la "justificación natural de la diferencia socialmente construída entre géneros y, en particular, de la división sexual del trabajo", volviéndose así "una construcción social que halla su principio en los princípios de división de la razón 
androcéntrica" (Bourdieu, 1998:16, 21) ${ }^{18}$ Ha sido esta visión patri-androcéntrica que alimenta la vieja dicotomía entre el lado formal y público ocupado por el hombre y el lado informal y privado femenino, valorizando lo primero en detrimento del segundo y, asímismo cuando sea detectable un cierto poder informal y "oculto" de la mujer, como lo refieren Riegelhaupt (1967), Reiter (1975) y Segalen (1980), el elemento que busca aún hoy reproducir la dominación masculina en la casa y sobre todo en la esfera pública. ${ }^{19}$

El análisis de las relaciones de explotación y dominación de la mujer deberá articular los conceptos de clase y de género y, teniendo en cuenta la constante tensión entre constreñimientos estructurales y elecciones racionales, deberá ser fundamentado, estructurado y articulado a tres niveles:

(i) al nivel socio-estructural, o sea, en la base de las condiciones objetivas de vida de los respectivos grupos de pertenencia de las mujeres -lo que engloba no sólo el género sino también la clase social, el género, la edad y demás recursos. De este modo, las relaciones de explotación y dominación de las mujeres habrían de ser analizadas con base en las contradicciones inherentes a los conflictos de clase y de género en la respectiva sociedad clasista y patriarcal, sea en términos diacrónicos, sea en términos sincrónicos, lo que, más allá de presentar puntos de convergencia con la explotación y dominación de hombres, puede presentar formas específicas de doble explotación y dominación de la mujer en la segmentación del mercado de trabajo, así como en la división del trabajo en los diversos sectores productivos, incluyendo el doméstico;

(ii) el nivel político-organizacional, que presupone relaciones de subyugación y dominación de las mujeres en el ámbito de las más diversas organizaciones desde el lugar de trabajo extradoméstico (comunidad, empresa/institución) a los partidos

${ }^{18}$ Es esta razón androcéntrica la que, por un lado, presenta la sexualidad femenina como un peligroso elemento incontrolable, 'diabólico', susceptible de 'victimizar' y 'vulnerabilizar' al propio hombre y, por otro, apelando a las metáforas de la masculinidad en torno del semen y de los órganos genitales (vg. 'hombre de cojones', "hombre de tomates"), confiere, con base en estos y en otros atributos fálicos, la superioridad al hombre (sobre sus semejantes) sobre la mujer.

${ }^{19}$ Tal como exponen, para la situación de las campesinas en pueblos de Grecia, Handman (1992), Dimen (1986) y Dubisch (1986) y, para las campesinas en Lugo (Galicia), Méndez (1988). 
políticos y otras organizaciones, pasando por el contexto organizacional doméstico, en que las mujeres, en su gran mayoría, priman por la (casi)ausencia de poder, deliberada o no, o detentan una posición jerárquicamente subordinada, lo que refuerza la dominación a nivel socio-estructural (del mismo modo que la organización de las propias mujeres contribuye a la emancipación o por lo menos a la minoración de los efectos de la dominación);

(iii) el nivel interactivo, el cual toca las propias vivencias y experiencias, interacciones y sociabilidades no sólo entre diversos grupos de pertenencia en el seno de cada género y entre miembros del género masculino y femenino, relaciones e interacciones en que las mujeres son a menudo desvalorizadas, desclasificadas o incluso discriminadas, lo que ocurre en los locales de trabajo, en las relaciones en público y sobre todo en las relaciones domésticas, en privado, o sea, en la micropolítica doméstica.

Aunque cada uno de estos niveles de análisis posea una relativa autonomía, se deberá dar prioridad analítica al nivel más abstracto (el socio-estructural), pasando por el organizacional, hasta el interactivo (o menos abstracto), articulando los dos conceptos -clase y género- y enfatizando uno u otro conforme a la configuración social en cuestión y en función de las situaciones concretas. En esta óptica, la dominación patriarcal asume formas diversas en consonancia no sólo con las relaciones de género sino también con los modos de producción presentes y, en particular, el modo de producción dominante en cada sociedad, tiempo y espacio.

Las corrientes organizacionales, de poder y sobre todo las perspectivas interaccionistas se han ocupado respectivamente del segundo y del tercer nivel y, por estar más próximo de la vida cotidiana, olvidan a menudo los parámetros estructurales de la explotación sexual y sobre todo de clase, atribuyendo con frecuencia al hombre 'culpas' y 'responsabilidades' cuando ellos son también, en mayor o menor grado, víctimas de los constreñimientos estructurales del sistema. En contrapartida, la visión marxista-leninista tradicional, al focalizar el análisis de la explotación y de la dominación femeninas, en términos socio-estructurales, con acento (casi) exclusivo en las contradicciones de clase, ensombrece, subestima o relega a segundo plano las 
vertientes organizacionales y sobre todo la dimensión interactiva. De este modo es así desresponsabilizado el hombre en las formas de dominación cotidiana, donde, más allá de las eventuales relaciones de explotación, ocurren con frecuencia asociaciones selectivas y prácticas de discriminación sexual, y en consecuencia en detrimento de la mujer. A este nivel, pueden con todo ocurrir excepcionalmente relaciones de dominación inversa por parte de mujeres hacia los hombres en el contexto doméstico, siendo recomendable evitar, por lo tanto, generalizaciones abusivas. $\mathrm{Si}$, en un considerable número de casas, concretamente en Portugal, se verifican, a la par de situaciones de relativa reciprocidad y simetría sexuales, situaciones de dominación, opresión y hasta violencia por parte de hombres frente a "sus" mujeres, también la dominación, aunque en términos minoritarios, del hombre por la mujer, es real, tal como pude constatar concretamente en el medio rural miñoto (Silva, 1991). La redistribución de la conflictividad intradoméstica $y$, en particular, conyugal, en la modalidad heterosexual, se centra alrededor del poder doméstico, el cual es construído a partir de la división social del trabajo fuera y dentro de casa, del tipo y grado de recursos materiales y simbólicos, como referí atrás.

La eliminación de las desigualdades de género, como realidad no estrictamente biológica sino social y politicamente construída, si, por un lado, presupone no sólo el cambio de mentalidades en el hombre y en la mujer como la construción de poder femenino a través de sus organizaciones específicas (de lo que, por ejemplo, la imposición legal de una cuota mínima de lugares puede ser un paso), por otro, tal objetivo estratégico convoca necesariamente el concurso de las luchas sociales con base en el criterio de clase, o mejor dicho, de los intereses de las clases y de los grupos sociales explotados y oprimidos.

Ante la imperiosa necesidad de la lucha por la igualdad de trato entre hombres y mujeres y de acceso práctico a derechos y oportunidades no sólo en la esfera extradoméstica y pública como en la doméstica y privada, urge, en términos teóricoprácticos y teniendo en vista su emancipación en cuanto ciudadanas y trabajadoras, un fecundo cruzamiento matrimonial entre feminismo y marxismo, el cual constituirá 
ciertamente el preludio y una contribución teórico-práctica para uno de los mayores cambios sociales y políticos en el próximo futuro. 


\section{BIBLIOGRAFÍA}

ABOTT, Pamela y WALlACE, Claire (1991), Gender, Power and Sexuality, Basingstoke: Macmillan.

ADORNO et al (1950), The Authoritarian Personality, Nova Iorque: Harper and Brothers.

ALMEIDA, Miguel Vale de [2000(1995)], Senhores de si. Uma interpretação antropológica da masculinidade, Lisboa: Fim de Século.

AMÂNCIO, Lígia (1993), "Género -representações e identidades" in SociologiaProblemas e Práticas, 14:127-140.

—(1994), Masculino e Femenino. A construción social da diferença, Porto: Afrontamento.

BECKER, Howard S. [1968(1963)], Outsiders -Studies in the Sociology of Deviance, Nova Iorque y Londres: The Free Press of Glencoe.

BOURDIEU, Pierre (1972), "Les stratégies matrimoniales dans le système de reproduction", in Annales, año XXVII, 4-5: 1105-1127.

-(1980), Le sens pratique, Paris: Minuit.

—(1998), La domination masculine, Paris: Seuil.

BOURDIEU, Pierre y PASSERON, Jean Claude (1977), Reproduction in Education, Society and Culture, Londres: Sage.

BRAVERMAN, Harry (1974), Labour and Monopoly Capital. The Degradation of Work in the Twentieth Century, Nova Iorque: Londres.

BRENNER, Johanna e LASLETT, Barbara (1986), "Social Reproduction and the Family" in U. Himmelstrand (org) Sociology: From Crisis to Science?, vol II, The Social Reproduction of Organisation and Culture: 116-131, Londres:Sage Publications. BRETTEL, Caroline (1991), Hombres que partem, mujeres que esperam. Consequências da emigración numa freguesia minhota, Lisboa: Publicaciones Dom Quixote. 
BROWN, Judith (1970), "A Note on the Division of Labor by Sex" in American Anthropologist, vol 72,5:1073-1078.

CABRAL, João Pina (1989), Filhos de Adión, filhas de Eva, A visión do mundo camponesa do Alto Minho, Lisboa:Dom Quixote.

CABRAL, João Pina (1991), Os contextos de Antropologia, Lisboa: Difel.

COLE, Sally (1991), Women of the Praia, Princeton, Nova Jersey: Princeton University Press.

COSTA, Adélia (1992), Representações de homens e mulheres, Portugal 1991, Lisboa: Comissão para a Igualdade e para os Direitos das Mulheres.

CROMPTON. Rosemary (2003), "Class and Gender beyond the "CulturalTurn", in Sociologia. Problemas e Práticas, 42: 9-24.

CUTILEIRO, José (1977), Ricos e pobres no Alentejo, Lisboa: Sá da Costa.

—(1988), "Honra, vergonha e amigos" in J.G. Peristiany (org) Honra e Vergonha.

Valores das sociedads mediterrânicas: ix-xxvii, Lisboa: Fundación Calouste Gulbenkian.

DESCAMPS, Paul (1935), Le Portugal: la vie sociale actuelle, Paris: Firmin-Didot et Cie.

DIAS, Isabel (1998), "Exclusão Social e violência doméstica: que relação?", in Sociologia: 189-205, Porto.

DIMEN, Muriel (1986), "Servants and Sentries:Women, Power and Social Reproduction in Kriovrisi”, in J. Dubisch (org), Gender \& Power in Rural Greece:5367, Princeton, Nova Jersey: Princeton University Press.

DINÂMIA (1997), Caracterización sociográfica das mulheres eleitas para as autarquias locales - 1993, Lisboa: STAPE: Ministério da Administración Interna.

DUBISCH, Jill (1986), "Introduction", in J. Dubisch (org) Gender \& Power in Rural Greece: 4-41, Princeton, Nova Jersey: Princeton University Press.

DU BOULAY, Juliet (1974), Portrait of a Greek Mountain Village, Oxford: Clarendon Press. 
Desigualdades de género: esbozo por un mapa proteórico

DURKHEIM, Émile [1974 (1895)], Las reglas del método sociológico, Madrid: Morata.

—[1977 (1893)], A divisão social do trabalho, Lisboa:Presença.

- (1983), Lições de Sociologia - a Moral, o Direito e o Estado, S. Paulo: T.A.Queiroz.

ENGELS, Friedrich $\{1980(1884)\}$, A origem da família, da propriedade privada e do Estado, Lisboa: Editorial Presença.

FERREIRA, Virgínia (1993), "Padrões de segregação das mulheres no emprego - uma análise do caso português no quadro europeu", in B.S. Santos (org) Portugal: um retrato singular:231-257, Porto:Afrontamento.

-(1981), "Mulheres, família e trabalho doméstico no capitalismo" in Revista Crítica de Ciências Sociales, 6:47-86.

—(1999), "Os paradoxos da situação das mulheres em Portugal" in Revista Crítica de Ciências Sociales, 52-53:199-227.

FIRESTONE O. S. (1976) A Dialéctica do Sexo, Rio de Janeiro: Labor do Brasil.

FLANDRIN, Jean-Louis (1984), Familles. Parenté, maison, sexualité dans l'ancienne société, Paris: Éditions du Seuil.

-(1983), Un temps pour embrasser. Aux origines de la morale sexuelle occidentale (VI-XI siècle), Paris:Seuil.

FOUCAULT, Michel (1994), História da sexualidad. I. A vontade de saber, Lisboa: Relógio d'Água.

FREUD, Sigmund [1975 (1946)], Abrégé de psychanalyse, Paris: Presses Universitaires de France.

GARNSEY, Elizabeth (1982), “Women's Work and Theories of Class and Stratification", in A. Giddens e D. Held (orgs), Classes, Power and Conflict, Londres: Macmillan Education.

GERALDES, Alice (1987), Gentes de minifúndio. Produção e reprodução social numa freguesia em mudança, Braga: Universidade do Minho (policopiado).

GOFFMAN, Erving (1974), Les rites d'interaction, Paris: Minuit. 
GONZALEZ, Juan Romero e ESPARCIA, Javier Perez (1992), Pobreza y desigualdad en los países en desarrollo, Madrid: Editorial Síntesis.

GOODY, Jack (1983), The Development of the Family and Marriage in Europe.

HANDMAN, Marie Elisabeth (1992), "La structure de la famille, dévolution des biens et statut paradoxal des femmes en Grèce", in A. Almeida et al (orgs), Familles et contextes sociaux, Lisboa: Centro de Investigación e Estudos de Sociologia.

HAREVEN, Tamara K. (1982), Family Time \& Industrial Time, Cambridge: Cambridge University Press.

HARRIS, Olivia e YOUNG, Kate (1981), "Engendered Structures: Some Problems in the Analisys of Reproduction", in J. S. Khan y J.R. Llobera (orgs), The Anthropology of Pre-Capitalist Societies: 109-147, Londres:MacMillan.

HARTMAN, Heidi (1982), "Capitalism, Patriarchy and Job Segregation by Sex" in A.

Giddens e D. Held (orgs), Classes, Power and Conflict: 446-469, Londres: MacMillan Education Ltd.

HELLER, Agnes (1986), "The Sociology of everyday life" in U.Himmelstrand (org) The Social Reproduction and Culture: 150-163, Londres: Sage Publications.

HÉRITIER, Françoise (1989), "Masculino/Femenino", in Enciclopédia Einaudi, vol 20, Parentesco, Lisboa: Imprensa Nacional-Casa da Moeda.

ITURRA, Raul [1983 (1976)], “Estratégias na organización doméstica da produción na Galiza rural» in Ler História, 1:81-109.

LEANDRO, Maria Engrácia (2001), Sociologia da Família nas Sociedads Contemporâneas, Lisboa : Universidad Aberta.

LEVI-STRAUSS, Claude [1982 (1949)], As estruturas elementares do parentesco, Lisboa: Vozes.

—(1977), A família como instituición, Porto: Rés.

LILJESTRÖM, Rita (1986), "Gender Systems and the Family", in U. Himmelstrand (org) Sociology: From Crisis to Science?, vol II, The Social Reproduction of Organisation and Culture: 132-149, Londres: Sage Publications. 
LUHMAN, Niklas [1982 (1970)], The Differentiation of Society, Nova Iorque: Columbia University Press.

MACHADO, Helena (1999), “'Vaca que anda no monte nión tem boi certo’: uma análise da prática judicial de normalización do comportamento sexual e procriativo da mujer", in Revista Crítica de Ciências Sociales, 55:167-184.

MARCUSE, Herbert [1963 (1955)], Eros et Civilisation, Paris:Éditions du Minuit. -[1968 (1964)], L’homme unidimensionne: essai sur l'idéologie de la société industrielle avancée, Paris: Minuit.

MARQUES, Ana Paula (2002), Jovens engenheiros: entre o diploma e o emprego, Braga: Universidad do Minho.

MARX, Karl [1974 (1967)], O Capital, Lisboa: Delfos.

MARX, Karl e ENGELS, Friedrich [1976(1846)], A ideologia alemã, Lisboa: Presença.

MEAD, H. (1934), Mind, Self and Society, from the Standpoint of a Social Behaviorist, Chicago: University of Chicago Press.

MEDICK, H. and SABEAN, D. W. (1984) (eds), Interest and Emotion: Essays on the Study of Family and Kinship, Cambridge/ Paris: Cambridge University Press e Editions de la Maleson des Sciences de l'Homme.

MEILLASSOUX, Claude (1977), Mujeres, celeiros e capitales, Porto: Afrontamento. MENDES, José M. Oliveira (1997), "Mobilidad social em Portugal: o papel da diferença sexual e das qualificaciones" in Revista Crítica de Ciências Sociales, 49:127156.

MEPAT (Ministério de Equipamento, do Planeamento e da Administración do Território) (1998), Portugal, uma visión estratégica para vencer o século XXI, Lisboa: Secretaria de Estado do Desenvolvimento Regional.

MILLET, K. (1974), Política sexual, Lisboa:Publicaciones Dom Quixote.

MÉNDEZ, Lourdes (1988), “Cousas de mulleres”. Campesinas, poder y vida cotidiana (Lugo 1940-1980), Barcelona: Ánthropos.

NENCEL, Lorraine (1994), "The Secrets behind Sexual Desire: The Construction of Male Sexuality in Lima, Peru", in Etnofor, VII, 2:59-75. 
MILLET, Kate (1974), Política sexual, Lisboa:Publicaciones Dom Quixote.

O’ NEILL, Brian Juan (1984), Proprietários, lavradores e jornaleiras, Lisboa: Dom Quixote.

ORTNER [1988(1972)], Sexual Meanings: the Cultural Construction of Gender and Sexuality, Cambridge: Cambridge University Press.

PARSONS, Talcott (1956), "Family Structure and the Socialization of the Child", in T. Parsons e R. Bales (orgs), Family, Socialization and Interaction Process: 35-131, Londres: Routledge \& Kegan Paul.

PERISTIANY, J. G. [1988 (1965)], "Introdución" y "Honra e vergonha numa aldeia cipriota", in J. Peristiany (org) Honra e Vergonha, valores das sociedads mediterrâneas: 3-10, 139-155, Lisboa: Fundación Calouste Gulbenkian.

PITT-RIVERS, Julian (1988), "Honra e posición social", in J.G.Peristiany (org) Honra e vergonha. Valores das sociedads mediterrânicas:11-61, Lisboa: Fundación Calouste Gulbenkian.

- [1997 (1977)], Anthropologie de l'honneur, Paris: Hachete.

RAPP, Rayna (1983), "Peasants into Proletarians from the Household Out: An Analysis from the Inter-section of Anthropology and Social History", in J.P. Menscher (org.) Social Anthropology of Peasantry: 32-47, Bombaim e Nova Iorque: Somaya Publications.

REICH, William [1972 (1942)], La psychologie de masses du fascisme, Paris: Payot. REITER, Rayna (1975), "Men and Women in the South France:Public and Private Domains", in R. Reiter (org), Toward an Anthropology of Women: 252-282, Nova Iorque: Monthly Review Press.

RIBEIRO, Manuela y SACRAMENTO, Octávio (2002), Prostituición feminina no espaço transfronteiriço ibérico -um caso particular de circulación de pessoas", in Cadernos do Noroeste, série Sociologia, Sociedad e Cultura, vol 18 (1-2), 205-227.

RIEGELHAUPT, Joyce (1967), "Saloio Women: an Analysis of Informal and Formal Political and Economic Roles of Portuguese Peasant Women", in Anthropological Quarterly, vol. 40, 3:109-126. 
ROBERTS, Richard (1984), “Women's Work and Women's Property: Household Social Relationship in the Maraka Textile Industry of the Nineteenth Century", in Comparative Studies in Society and History, vol. 26, 2:229-250.

SANTO, Moisés Espírito (1980), Freguesia rural ao norte do Tejo, Lisboa: IED.

SANTOS, Boaventura de Sousa (1994), Pela mión de Alice. O social e o político na pós-modernidde, Porto: Afrontamento.

SCHNEIDER, Jane (1971), "Of Vigilance and Virgins: Honour, Shame and Access to Ressources in Mediterranean Societies", in Ethnology, vol. X, 1:1-24.

SCOTT, James (1990), Domination and the arts of resistance: Hidden transcripts, New Haven e Londres: Yale University Press.

SEGALEN, Martine (1980), Mari et femme dans la société paysanne, Flammarion.

- [1983 (1980)], Love and Power in the Peasant Family. Rural France in the Nineteenh Century, Chicago: The University of Chicago Press.

SILVA, Manuel Carlos (1987), "Camponeses nortenhos: 'conservadorismo' ou estratégias de sobrevivência, mobilidad e resistência", in Análise Social, 97:407-445.

—(1991) "Casa e casas em espaço rural minhoto: o poder doméstico" in Cadernos do Noroeste, vol 4(6-7):79-99.

-(1998), Resistir e adaptar-se. Constrangimientos e estratégias camponesas no noroeste de Portugal, Porto:Afrontamento.

-(1998), "Prostituição feminina: uma primeira abordagem para uma pesquisa", in Cadernos do Noroeste, vol 11, 1:227-244.

-(1999), "A luta pela igualdade social: por uma articulação conceptual entre classe e género", in Fórum A situación das mujeres no limiar do século XXI, Lisboa:Editorial Avante.

-(2002), "Conflitos interfamiliares e 'mal de inveja", in Análise Social, vol XXXVII, 162:209-241.

SILVA, Manuel Carlos y VAN TOOR, Marga (1988), "Camponeses e patronos: o caso de uma aldeia minhota", in Cadernos de Ciências Socales, 7:51-80. 
SILVA, Manuel, MACHADO, Helena y SILVA, Susana (2002), "Direito, ciência e corpo feminino: a prostituição como 'objecto de fronteira'", in Cadernos do Noroeste, serie Sociologia, Sociedad e Cultura, vol 18, 4:183-203.

SOBRAL, José Manuel (1999), Trajectos: passado e presente na vida de uma freguesia da Beira, Lisboa: Instituto de Ciências Sociales da Universidade de Lisboa.

TORRES, A. C. (2001), Sociologia do Casamento. A Família e a Questão Feminina, Oeiras, Celta Editora.

VIEGAS, José Manuel Leite y FARIA, Sérgio (1999), As Mulhes na Política, Lisboa: Imprensa Nacional-Casa da Moeda.

—(1999), "Participação política feminina. Percursos, constrangimentos e incentivos" in Sociologia - Problemas e Práticas, 30: 55-87.

WALL, Karin (1998), Famílias no campo: passado e presente em duas freguesias do Baixo Minho, Lisboa: Dom Quixote.

WALL, Karin y ALMEIDA, Ana Nunes (2001), "Família e quotidiano: movimentos e sinais de mudança”, in J.M. Brandão de Brito (org) O país e a revolución: 277-307, Lisboa: Círculo de Leitores.

WALBY, S. (1997), Gender Transformations, Londres: Routledge.

WEBER, Max [1978(1920)], Economy and Society, editado por G. Roth e C. Wittich, Berkeley y Londres: University of California Press.

WEEKS, J. (1986), Sexuality, Londres y Nova Iorque: Tavistock Publications.

WIARDA, Howard (1977), Corporatism and Development. The Portuguese Experience. Massachussetts: The University of Massachussetts Press.

WILLEMS, Emilio (1963), “On Portuguese Family Structure”, in K. Ishwaran (org.), International Studies in Sociological and Social Anthropology, vol. I, 65-79, Leiden: E. J. Brill.

ZARETSKY, E. (1973), Capitalism. The Family and Personal Life, Nova Iorque. 